DE DE GRUYTER

OPEN

G

Germinal Isern*

Clark University

Giuseppe Sena

MassBay Community College
Journal of Intercultural Management

Vol. 6, No. 3, September 2014, pp. 187-196

DOI 10.2478/joim-2014-0029

\title{
Technical, Organizational and Cross-cultural issues associated with the deployment of Customer Relationship Management (CRM) in Transnational and Global Multicultural Organizations
}

\begin{abstract}
In the past few years the way in which, organizations, companies and corporations structure themselves has given a 180 degrees turnaround, switching from a structure based in products to a structure based in customers. The first big change was the introduction and use of Enterprise Resource Planning Systems (ERP) like SAP and Oracle. Those ERP systems changed the way in which the information was managed in large corporations including now a central database and visualizing the structures and functions of the corporation by business processes and not by business areas. Also lately with the advent of the WEB 2.0, the boom of the social media and the big data analytics areas, business, marketing and the relation with the customer has totally changed.

One of the most important drivers for this turnaround is the adoption of Customer Relationship Management (CRM). CRM is supporting software designed to improve the relation with the current customers (loyalty) using modern social media and massive marketing technologies.

This paper introduces the organizational issues of cross-cultural communication associated with the integration between marketing, customer service, and complaint management with information technology. In highly competitive environments a lot of organizations intent to construct a relationship with their current customers, since the cost involved in capturing new ones is a lot higher than the cost of retaining the current ones. The most crucial factor is the understanding of the clients and their values, norms,
\end{abstract}

* gisern@clarku.edu 
traditions, language, religions, perceptions, thoughts in few words their culture. So this cultural dimension analysis is essential and the development of a formal taxonomy or cultural concern framework a need. This paper will deal with the dimension concerns from the technical, cultural and organizational point of view needed to build this framework in order to avoid the terrible consequences of a wrong interaction with the customers due to cultural issues.

Key words: Customer Relationship Management, CRM, Culture, Cross-Cultural Communication.

\section{Introduction}

The real essence of the IT revolution and, in particular, the WWW is the great chance to design plans to create better relationships with the users, clients or customers than has been previously possible in the off-line no Internet world. This perfect combination of the ability to give fast response directly to customer requests and at the same time give to the customer a highly interactive, tailored experience makes possible that companies now may have a greater capacity to establish, care, and sustain long-term customer relationships than ever before. The final goal is to translate these relationships into greater profitability by increasing loyalty, confidence, faith, repeat purchase rates and reducing customer acquisition costs.

The imperious necessity to have a better understanding of the customer behavior and centralize the attention on those customers who can deliver long-term profits has changed the way in which marketing sees the world. Marketers have been traditionally prepared and indoctrinated to acquire customers, either new ones or those who belong to the group of competitors' customers. This methodology required lots of mass advertising and price-oriented promotions. Nowadays, the emphasis is over retention, requiring a new frame of mind and obviously a new set of tools.

With the introduction of ERP systems in the majority of the organizations, the increase in the level of IT knowledge, the social media revolution and the shift of the economy to a global one the way in which companies see the relation with the current and future customers has changed. Marketing is not what use to be, customer service, complaint management and retention is essential for today business. Organizations not only need to capture new customers, they need to keep the ones that they already have. They do not only need to capture and retain customer in their local markets, they need to go out and deal with them in the whole world. CRM, Customer relationship Management might provide the means to reach this goal but we need to understand the cultural dimensions in the interaction with the new global market and how we can reach a level of understanding that allows the CRM global developers to design and implement effective and efficient CRM Global systems.

Cultural dimensions are identified as a critical influence on the potential failure or success of the process of Global Software Development, IT outsourcing, 
Information Systems in general and Customer Relationship Management Systems (CRM) in particular. Some CS scientist have indicated possible ways in which IT management and specifically CRM systems development can accommodate these dimensions or solve the problems they may pose. Ali and Alshawi (2005) have proposed a framework for the management of CRM systems implementation in the multinational environment with the cultural problems consideration in mint. In this paper we will analyze that framework by conducting a qualitative comparison of the technical, organizational and cross-cultural issues associated with the deployment of Customer Relationship Management (CRM) in transnational and global multicultural Organizations.

\section{Customer Relationship Management.}

CRM could be defined as a way to identify, acquire, and retain customers. Also as a technology-enabled business strategy whereby companies leverage increased customer knowledge to build profitable relationships, based on optimizing value delivered to and realized from their customers. For some authors, it is a way of automating the front office functions of sales, marketing, and customer service. For some software or applications vendors CRM is whatever product they are commercializing.

The variety of definitions is a result of differences in perspectives. The first and second definitions are based on a new business perspective of more and more competition that is moving or even forcing companies to center on their customers. The second and third definitions are based on the new phenomenon of the association or integration of separate applications such as Sales Force Automation and Customer Service Support into Broad Enterprise Applications and ERP systems. The fourth is a result of major software vendors situating their information technology offers and services under the CRM denomination, in order to use it as a marketing strategy and take advantage of the growth of the CRM market.

Our definition clearly emphasizes the links between customer knowledge and increased profits and our work tries to heavy promote the idea that customer knowledge in or new global markets implies cultural dimensions customer knowledge. The definition also highlights that CRM is about creating value for customers and you cannot create value with really knowing the customers and their cultural dimensions. CRM by itself is a not a technology, but technology is needed to enable CRM. Technology and more specifically Information Technology makes it possible to integrate the large volumes of customer data that are required for CRM into information and to efficiently transform this information into useful knowledge, that could build the intelligence to acquire, satisfy and retain customer.

CRM is important due to the transition occurring in the competitive environment. Thanks to the Globalization and the Internet competition can now come from around the world, moving the power and choice to the customer. 
Companies must take the decision whether to compete on the basis of price in a cutthroat commodity market, or on the basis of customer relationships created through a superior value proposition, since product quality and features are not very differentiated. This last business model is what CRM is all about. It helps you to sense ever more precisely the needs of your customers, and to respond to those needs with highly targeted offerings and marketing messages.

One of the most important concepts about nowadays marketplace on which CRM must be based is loyalty and captivity, but the customer relationship nature and the change in the expectations of the customer are also very important concepts.

A loyal customer chooses a company's product even there are reasonable competitive alternative products. Customers choose a company that it offers a superior value proposition, either in the product itself, or in the interactions they experience during company-customer life cycle. Captive customers have no choice, either because there is no alternative or because they are "locked-in" with the service offered by the company.

For companies both types of customers, clients or users can be profitable. However, a captive one strategy can be not sustainable and more in a global market with big cultural differences. If it results in customers being taken for granted or worse yet, exploited or offended by some misleading campaign or message, they will most likely defect at the first chance to do it. The proposed framework assumes the development of customer relationships based on loyalty cannot be achieved without time, respect and deep knowledge of the cultural differences.

- A CRM strategy in relation to the change of the customer expectations is not just about deploying "point solutions" such as a Sales Force Automation system, or setting up a web site. It is the total evolution of a business along a number of dimensions, moving from a:Model focused on making and selling products to a model sensing customer needs and responding with targeted product and service offerings (“Knowing your customer").

- Mass marketing like television to marketing to segments of one like web portals or oriented social media.

- Business-centric interactions to customer-centric interactions.

The customer relationship is basically based on the exchange of value for money, but the cultural concept of trade and the value of money is not the same across different cultures. The relationship between the parties can be expected to continue only if both parties benefit without affecting their beliefs, traditions and culture. Usually the partner willing to finish the relation is the one who holds more power. Today, power is clearly moving to the customer side as markets become more efficient and more competitive. The value that could make a difference between two companies is based on the customer's interaction experience with them. 
Figure 1

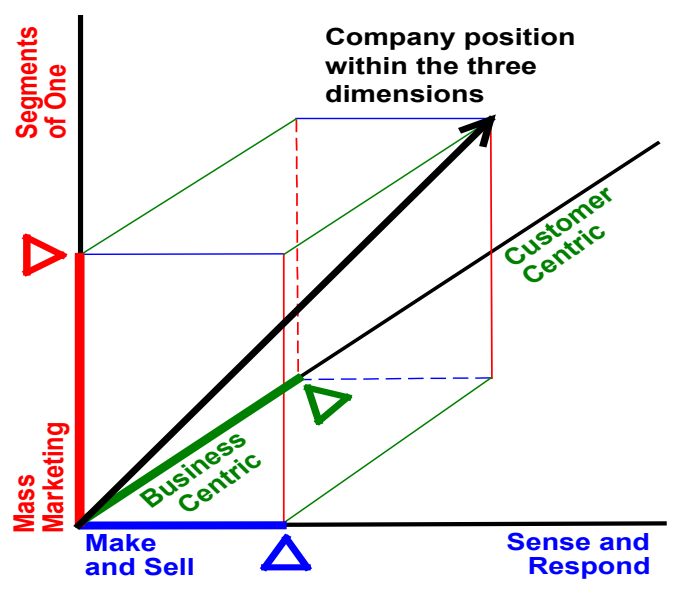

Source: own research.

In the CRM context, the partners are the company and the customer, but the company is just a virtual entity and of course not having relationships as an individual, nor one-to-one relations or a physical person in the company establishing the relation in name of the company. So actually the real relation is just the one that the customer perceives from the company, and here again is where cultural factors might disturb the perception or the intention of the relation from the company to the customer. The final state of the relation company-customer is the final result of all the interactions that the customer has directly or indirectly with the company. Therefore, Customer Relationship Management is the administration of the ability to interact with the customer with positive interactions that will reinforce the relationship. This interaction is impossible if the company is not able to understand the cultural dimensions and the potential cross cultural conflicts that may arise from the wrong interaction with customer situated all across the planet. Global, transnational organizations and even local corporations that have to deal with a market target that is spread along different cultures, religions, languages, traditions, genders, etc must include a deep analysis of such characteristics in order to adapt their use of the Information System, Information Technology, Marketing Strategies and in a nut shell CRM in order to acquire and maintain the base of customers and consider themselves as a profitable organization. Nowadays a deeply knowledge of the customer as individuals and as a members of a social group and how to manage the interaction between the company and the customer is critical for success. 


\section{Cultural Dimensions and CRM Systems.}

Cultural dimensions are identified as a great influence on the potential success of IT systems and especially in Customer Relationship Management Systems (CRM). This position paper will try to describe the factors that transnational and global companies must consider from the technical, organizational and cross cultural communication point of view in order to establish a successful relationship with the customers. These aspects must also be considered for companies which target market is spread across several different social groups, with different perspectives, cultures or traditions.

In a competitive market, companies try to build a relationship with their existing customers; building a relationship with customers is a socio-technical process. The most important factor in that process is to understand how that customer values, norms, thoughts, perceptions are alike. Multinational companies have to deal with customers from different cultures. CRM systems in global organizations are designed to attract new customers, increase customers' value and retain customers, and in all cases these may be with different customers and from different cultures.

Hofstede's work about cultural dimensions is the first reference about culture within Information Systems literature (McCoy 2003), Isern (2013). Ali and Alshawi (2005) described a comprehensive cultural dimensions framework, based on Hofstede's cultural dimensions. There is a lot of publications in relation of how to see the world as a melting pot of races, religions, traditions in a nutshell cultures; giving a set of general concepts and ideas, however, the typologies of culture do have inherent weaknesses since they do not show a clear reflection of the diversity of values and attitudes that may exist in a country or even in a region of a country, nor do they give an explanation of how cultures have developed along the time. This paper wants to raise the level of awareness about the limitations that need to be considered, when analyzing the impact of culture on the use of CRM systems (Skok and Legge 2001).

We'll try to describe the intercultural factors involved. In the age of globalization the market is becoming increasingly cross-culturally integrated making understanding and expertise in cross-cultural communication more crucial for executives, business leaders, workplace managers, and standard employees.

In order to get a deeper understanding of and acquire skills in intercultural encounters at the workplace, those engaged in it must gain practical knowledge of the factors that impact cross-cultural communication and how does factors impact in different CRM systems implementation. According to experts in the field of intercultural communication, some of those factors ( Isern 2013) include:

The Cultural Identity Factor: Culture is the values, attitudes, and ways of doing things a person learns during the socialization process in the particular place where they were brought up as a child. The cultural identity factor impacts cross-cultural communication because the norms and practices a person acquires and practices in 
their country and local community will be different from and clash with the norms and practices of others sees as common in their own country or region.

The Racial Identity Factor: The racial identity factor refers to how one's conscious membership in a particular race affects how they interact with others or how to perceive what comes from different cultures.

The Ethnic Identity Factor: The ethnic identity factor highlights the role ethnicity plays in how their ethnic background affects the interpretation of facts and the communication process in general.

The Gender Role Identity Factor: This means that communication between members of different cultures is affected by how different societies view the roles of men and women.

The Individual Identity Factor: This means that how a person communicates with others from other cultures depends on their own unique personality traits and how they esteem themselves.

The Social Class Identity Factor: The social identity factor refers to the level of society that person was born into or references when determining who they want to be and how they will act accordingly.

The Age Identity Factor: The age identity factor refers to how members of different age groups interact with one another. In old terms this might be thought of in terms of the generation gap.

The Roles Identity Factor: The roles identity factor refers to the different roles a person plays in his or her life including their roles as a husband or wife, father, mother or child, employer or employee and so forth.

Let's first describe Hofstede's work and other author's contributions to later summarize and outline some conclusions and recommendations.

\section{Culture, cultural theories and intercultural factors}

Culture could be defined as the integrated pattern of knowledge, belief, and behavior that depends upon the capacity for learning and transmitting knowledge to succeeding generations. Culture is the learned values and behaviors shared by a group of people and play a vital role in how a person performs his or her work based on individual patterns of thinking, feeling, and acting. Culture has visible attributes like dining, clothing, religious rituals, architectures, or sports while invisible attributes comprise of orientations to environment, time, communication, space, power, individualism, competitiveness, structure, and thinking. Several theories have been proposed to categorize cultural differences. As the primary source of intercultural factors, we used the works of E. T. Hall [7], G. Hofstede [9, 10], Fiske [4,5] and F. Trompenaars \& Charles Hampden-Turner [16].

Hofstede's Cultural Dimensions

- Power Distance (PDI),

- Individualism/Collectivism (IDV)' 
- Uncertainty Avoidance (UAI),

- Masculinity/Femininity (MAS),

- Short-term or Long-term Orientation (LTO).

These dimensions give insight to different national cultures.

\section{E. T. Hall's Cultural Factors}

E.T. Hall, based on anthropological analyses identified key cultural factors. These are classified into High Context and Low Context based on time and space. Hall also looked at the way cultures handle time - Mono-chronic cultures versus Poly-chronic cultures.

\section{Trompenaars \& Hampden-Turner Dimensions}

- Universalism vs. Particularism

- Individualism vs. Communitarianism

- Neutral vs. Emotional

- Specific vs. Diffuse

- Achievement vs. Ascription (attitude toward titles, degrees...)

- Sequential vs. Synchronic cultures

- Internal vs. External control.

Fiske forms of socialite

- CS: communal sharing: do people treat all members of a category as equivalent.

- AR: authority ranking: do people attend to their positions in a linear ordering.

- EM - equality matching: how people keep track of the imbalances among them.

- MP: market pricing, how people orient to ratio values.

Hofstede's cultural dimensions help CRM and marketing designers to recognize individual and group behaviors in different countries. E.T. Hall's adds the dimensions based in context concept of time and space. Trompenaars and HampdenTurner have a contradict Hofstede's cultural dimensions approach because they view culture as process and propose that ,culture is the way in which a group of people solve problems and reconcile dilemmas'. Hofstede analyses the variables of national cultures, whereas Trompenaars and Hampden-Turner are involved in the processes of cultural creation. Many other researchers such as Philippe d'Iribarne [17] have the same approach as Hall but with an ethnographic method for sensemaking. Vaara [18] has broadened these cultural studies with an epistemological approach where they state that culture and cultural differences exist only when people become aware of it in their social interactions.

Stahl (2003) differentiated two dimensions of culture. The first one states that different cultures are fundamentally and possibly irreconcilably different, whereas the second one states that all cultures share some universal attributes. Stahl has concluded that, despite obvious difference in cultures, there are similarities that are 
based on human nature. Ali \& Alshawi, 2004 outline three types of culture. First, there is the culture that a society shares (national culture), a set of core values that shape the behavior of individuals as well as the whole society. Second, there is the culture on a smaller level, namely organizational culture (Adler 1997; Bagchi and Cerveny 2003). Third, there is the individual level of culture (Dorfman and Howell 1988) that describes the effects of national culture on individual behavior.

\section{Proposed factors to be included in the cultural dimensions and a critique of Hofstede framework}

Despite the common use given to Hofstede cultural dimensions research, his work can be seen as only one way of looking to culture within the Information Systems and Technology discipline (McCoy, 2003; Ali and Alshawi 2004a, 2005). We must make a deeper analysis of the impact of the culture dimensions on the CRM systems implementation and operation Walsham (2002) stated that the Structure Analysis Theory of Giddens could be used to analyze the similitude and difference in a variety of cultural sub-groups and even individuals. Ali \& Alshawi (2005) proposed many cultural dimensions in their framework for the management of CRM implementation and operation in the multinational environment. A summary of these cultural dimensions and their definitions were shown in the previous part

\section{Culture, Structures Theory and Information Systems}

The theory of Giddings as described by Walsham, has been very influential in the social sciences, receiving also considerable attention in the IS field. We propose to use this theory of Giddings plus the models of Hofstede, Fiske, Trompenaars and Hampden-Turner, E.T. Hall, Philippe d'Iribarne, Vara plus the contribution of Adler, Ali and Alshawi with the summary of Walsham to propose a more formal and general strategy to review cross cultural factors in the implementation of CRM systems.

\section{Conclusions and Future Work}

This was a position paper just to describe potential factors involved, the set of separate theories and foundations that associate Customer Relationship Management system implementation with Cross-Cultural Communication, technological and Organizational issues so there is not much to conclude, this early in our study. But we set the parameters for the future study that we hope will produce a systematic approach in order to configure and enact CRM system implementation for Transnational, Global and multicultural target organizations being able to respect cultures, nations and groups involved and reaching the maximum effectiveness and efficiency in the interaction with the customer.

\section{Bibliohraphy}

Adler, N. (1997), International dimensions of Organizational Behavior. ITP. 
Ali, M. and Alshawi, S. (2004a), A Cultural Approach to Study Customer Relationship Management (CRM) Systems, CISTM 2004, Alexandria, Egypt.

Ali, M. And Alshawi, S. (2005), Cultural Universality Versus Particularity Within eCRM Systems: A Special Case Of Information Systems, EMCIS 2005, Cairo, Egypt.

Bagchi, K. and R. Cerveny (2003), The Influence of National Culture in Information Technology Product Adoption, AMCIS 2003, Tampa, Florida, USA.

D'Iribarne P., (2009), Conceptualizing national cultures: an anthropological perspective, http://inderscience.metapress.com/app/home/contribution.asp?referer $=$ parent\&backto $=$ issue, 2,6 ; journal,4,12;linkingpublicationresults, 1:120713,1

Dorfman, W.P., Howell J.P. (1988), Dimensions of National Culture and Effective Leadership Patterns: Hofstede Revisited. Advances in International Comparative Management, 3, 127-150.

Fiske A.P. (1992), The Four Elementary Forms of Sociality: Framework for a Unified Theory of Social Relations, "Psychological Review", vol. 99, pp. 689- 723,.

Fiske A.P. (1991), Structures of Social Life: The Four Elementary Forms of Human Relations. New York: Free Press (Macmillan).

Giddens, A. (1979). Central Problems in Social Theory, Macmillan, Basingstoke, UK.

Giddens, A. (1984). The Constitution of Society, Polity, Cambridge, UK.

HallE.T. (1976), Beyond culture. New York: Anchor Books/Doubleday.

Hofstede G. (1980), Culture's consequences. Beverly Hills, CA: Sage.

Hofstede G. (1997), Culture and organizations--Software of the mind. McGraw-Hill.

Hofstede G.J., Pedersen P.B., Hofstede G. (2002), Exploring culture; exercises, stories and synthetic cultures. Yarmouth, Maine, USA: Intercultural Press,.

Isern G. (2014), Intercultural Communication and Management Factors and Their Impact to the Process of Global Software Development for Virtual and Non-Virtual Teams. "Journal of Intercultural Management", Volume 6 Number 1 January SAN: Warsaw.

Russell S. (2001), Winer. Customer Relationship Management: A Framework, Research directions and the future. April

Sathish, S., S. L. Pan, et al. (2002). Customer Relationship Management (CRM) Network: A New Approach to studying CRM. AMCIS, Dallas, USA.

Skok, W. and M. Legge (2001), Evaluating Enterprise Resource Planning (ERP) Systems using an Interpretive Approach. SIGCOPR2001, San Diego, USA.

Stahl, B. C. (2003), Cultural Universality versus Particularity in CMC. Proceedings of the Ninth Americas Conference on Information Systems, USA.

Trompenaars F., Hampden-Turner C. (1997), Riding The Waves of Culture, 2 ed. New York: McGraw- Hill Trade,

Vaara, E. (2000), Constructions of Cultural Differences in Post merger Change Processes: A Sense making Perspective on Finnish-Swedish Cases, "Management", 32, pp.81-110

Walsham, G. (2002). Cross-Cultural Software Production and Use: A Structurational Analysis. MISQuarterly, 26(4), 359-380. 